LICENÇA CC BY:

Artigo distribuído sob os termos

Creative Commons permite uso e distribuição irrestrita em qualquer meio desde que o autor credite a fonte original.

\title{
O PROGRAMA JOVEM DE FUTURO DO INSTITUTO UNIBANCO PARA O ENSINO MÉDIO: DECORRÊNCIAS DO IMBRICAMENTO ENTRE PÚBLICO E PRIVADO
}

THE "JOVEM DE FUTURO" (YOUTH OF THE FUTURE) PROGRAMOF INSTITUTO UNIBANCO FOR HIGH SCHOOL EDUCATION: OUTCOMES OF PUBLIC-PRIVATE SECTOR PARTNERSHIPS

EL PROGRAMA JOVEN DE FUTURO DEL INSTITUTO UNIBANCO PARA LA ENSEÑANZA SECUNDARIA: CONSECUENCIA DE LA IMBRICACIÓN ENTRE PÚBLICO Y PRIVADO

Simone Sandri ${ }^{1}$

Monica Ribeiro da Silva²

${ }^{1}$ Doutora em Educação pela UFPR. Docente do Curso de Pedagogia da Universidade Estadual do Oeste do Paraná (UNIOESTE), Cascavel, PR, Brasil.

${ }^{2}$ Doutora em Educação pela PUC/SP. Docente do Programa de Pós-Graduação em Educação da Universidade Federal do Paraná (UFPR), Curitiba, PR, Brasil.

\begin{abstract}
Resumo: Neste texto analisamos as decorrências da relação público-privada ao se associar um programa que faz parte de uma ação da política educacional federal a um programa oriundo do setor empresarial. A análise de documentos relativos ao Programa Ensino Médio Inovador e ao Programa Jovem de Futuro permitiu identificar um imbricamento entre as duas ações que têm como resultados uma preponderância do privado sobre o público com efeitos sobre a formação dos indivíduos e sobre a gestão escolar.
\end{abstract}

Palavras-chave: Ensino Médio; Programa Ensino Médio Inovador; Programa Jovem de Futuro; relação público-privado.

\begin{abstract}
In this text we analyze the consequences of a public-private sector partnerships that links a program that is part of a federal educational policy action with a program originating in the business sector. The analysis of documents relative to the Programa Ensino Médio Inovador (Innovative Secondary School Program) and the Programa Jovem de Futuro (Youth of the Future) enabled us to identify areas of overlap between the two actions, resulting in the prevalence of the private over the public sector, with effects for the training of individuals and school management.
\end{abstract}

Keywords: Secondary School; Programa Ensino Médio Inovador; Programa Jovem de Futuro; Public-private sector relationship.

Resumen: En este texto analizamos las derivaciones de la relación público-privado implicada en la asociación de un programa que forma parte de una acción de política educativa federal y 
de un programa oriundo del sector empresarial. El análisis de documentos relativos al Programa Ensino Médio Innovador [Programa Enseñanza Secundaria Innovadora] y al Programa Jovem de Futuro (Programa Joven de Futuro) permitió identificar una imbricación entre las dos acciones que resulta en un predominio de lo privado sobre lo público con efectos sobre la formación de los individuos y sobre la gestión escolar.

Palabras clave: Enseñanza Secundaria; Programa Ensino Médio Inovador; Programa Jovem de Futuro; relación público-privado.

\section{Introdução}

O texto trata da relação público-privada no contexto de políticas educacionais voltadas para o Ensino Médio, particularmente no que diz respeito à associação entre o Programa Ensino Médio Inovador (ProEMI) ofertado pelo Ministério da Educação, em parceria com as secretarias estaduais de educação e o Projeto Jovem de Futuro (PJF) do Instituto Unibanco (IU). O recorte analítico se refere às concepções de formação humana e de gestão para a escola pública, decorrentes desse imbricamento, doravante denominado ProEMI/JF.

O ProEMI se configurou como uma política pública para o Ensino Médio, proposta pelo Ministério da Educação (MEC), por meio da Portaria n. 971, de 09 de outubro de 2009. O Programa tem como principal objetivo induzir mudanças curriculares por meio de redesenhos dos currículos que envolvem as dimensões do tempo, do espaço e dos saberes escolares (BRASIL. MEC. SEB. ProEMI, 2011). O Projeto Jovem de Futuro surgiu no final do ano de 2006. Entre 2007 e 2008, iniciou suas "experiências pilotos" nos estados do Rio Grande do Sul, São Paulo, Minas Gerais e Rio de Janeiro. Após essas experiências, o PJF foi validado pelo MEC como uma "tecnologia de gestão escolar" e consta no "Guia de Tecnologia Educacional" (2015).

Em 2012, o MEC e o IU assinaram o "Termo de Cooperação Técnica de Implantação do Programa Ensino Médio Inovador/Jovem de Futuro", que possibilitou, formalmente, a vinculação entre ProEMI e PJF. Tanto o ProEMI como o PJF são implementados a partir das adesões dos governos estaduais. Diante desse quadro, a pesquisa que deu origem ao presente texto buscou responder às seguintes questões: Quais as formas/conteúdos que assume o ProEMI em decorrência de seu imbricamento com o PJF? Que concepções e práticas formativas e de gestão resultam da relação público-privada que caracteriza esse imbricamento? E como hipótese orientadora da análise, trabalhamos com o seguinte enunciado: O imbricamento entre ProEMI e PJF ganha formalidade na chamada parceria entre o MEC e o Instituto Unibanco e entre esse e as SEDUCs dos entes federados que aderem as duas propostas em conjunto. Esse imbricamento dificulta a percepção das contradições da relação público-privada, em que o PJF, sob a lógica privada, assume uma posição aparentemente de representante do "bem comum", ao ser apresentado como uma proposta de interesse público. 
Para caminhar no sentido de respondermos nossas problemáticas, optamos pela análise teórica fundamentada nas concepções gramscianas de Estado, de conceito de hegemonia e de intelectual orgânico. A definição gramsciana de Estado localiza nas sociedades modernas a presença de outra esfera de poder além do Estado stricto sensu ou sociedade política, esfera esta que Gramsci chamou de sociedade civil. A complexidade das relações políticas modernas, que Gramsci chama de ocidentalização, em referência às sociedades Ocidentais, fez com que esse teórico notasse que o Estado moderno demandava algo mais que a dominação, a coerção, a ditadura, isto é, o Estado moderno necessita do consenso entre governantes e governados para ser legítimo e esse consenso é produzido na sociedade civil.

A demanda pelo consenso social, pela direção cultural e política de um grupo ${ }^{1}$ e/ou classe social sobre outra é definida por Gramsci de hegemonia. Por sua vez, a constituição e/ou intensificação da hegemonia, segundo Gramsci, requer a composição de um grupo de intelectuais organicamente vinculados à ideologia e à cultura de classe/ grupo que busca desenvolver ou intensificar o processo de direção da sociedade. Pois é nesse sentido que localizamos as instituições representantes do empresariado brasileiro, tal qual o Instituto Unibanco.

Ainda com base em Gramsci, compreendemos que o público não se resume ao Estado stricto sensu e o privado não se resume à sociedade civil, mas público-privado é dimensão de uma relação social que permeia o conjunto do Estado. Por isso, tomamos como pressuposto para a análise que as ações específicas do Estado stricto sensu ora são predominantemente de perspectiva pública, no sentido de atender aos direitos sociais e com a intenção de se voltar para todos e ora são predominantemente de perspectivas privadas (como políticas financeiras voltadas aos bancos, aos conglomerados empresariais ou às demais políticas públicas sob perspectiva privada). Assumimos, também, que a sociedade civil demanda posições e organizações de interesse público e de interesse privado, questões estas que disputam espaços no contexto das políticas públicas. $O$ texto está estruturado, além desta Introdução, em três outras seções. Na primeira, trazemos uma discussão conceitual acerca de público e de privado. Nas segunda e terceira, considerando as premissas definidas nesta Introdução, bem como no debate teórico sobre a relação público-privado, analisamos o ProEMI/JF. Ao final, a título de considerações finais, retomamos a hipótese anteriormente enunciada.

\section{Sentidos conceituais e teóricos de "público" e} "privado"

Para discutirmos o "público" e o "privado" e/ou a relação "público-privada" nas especificidades do ProEMI/JF, partirmos de algumas definições desses termos apresentados no dicionário de Língua Portuguesa, no dicionário jurídico e em reflexões teóricas sobre esses conceitos. 
Público vem do latim publicus, de populicus, de populus (povo, habitante) e, de modo geral, significa

[...] o que é comum, pertence a todos, se mostra que não pertence nem se refere ao indivíduo ou a particular. Assim, extensivamente, público equivale a notório, geral, publicado, divulgado, conhecido. No entanto, como o anotamos acima, público e comum possuem acepções próprias e inconfundíveis. Público é o que pertence a todo o povo, considerado coletivamente, isto é, tido em sua expressão de organismo político.

Comum é o que pertence ou se estende distributivamente ao povo ou a todos, considerados como indivíduos. Pode ocorrer que público e comum tenham aplicação conjunta, visto as duas qualidades se apresentarem no mesmo fato: os logradouros são públicos e comuns. Públicos, porque não pertencem a ninguém em particular, mas a todos; comuns, porque todos participam de suas utilidades. As rendas do Estado, que servem a seus interesses, porém, são públicos, como públicos são órgãos que o administram; já os serviços que o Estado presta são comuns, porque todos podem fruir suas utilidades. O público opõe-se ao privado, enquanto que o comum ao particular. Público, além do sentido vulgar, na linguagem jurídica, é tomado na acepção de próprio ou pertinente ao Estado, revelando a subordinação ou a afetação que incide sobre todas as coisas ou fatos, qualificados ou considerados como tal. Desse modo, no sentido de público integra-se o de autoridade do Estado ou poder do Estado, mostrando sua identificação com a própria coisa ou com o próprio fato, a que, intimamente, se ligou. Deste sentido de público é que se gerou o verbo publicizar. E, nesta razão, é que o conceito público não se refere simplesmente à condição de ser coisa de interesse comum ou de interesse coletivo, mas à íntima conexão ou à identificação da própria coisa com as finalidades do Estado e os interesses particulares e, mesmo, coletivos (DE PLÁCIDO; SILVA, 2004, p. 1134) [Grifos nossos].

As acepções etimológica e jurídica para a ideia de público indicam o seu caráter geral de "ser de todos"2 ou possibilitar o acesso de todos, com isso, é antagônico ao privado/individual pelo fato de o público se referir ao coletivo. Outra acepção encontrada no vocabulário jurídico é o de vincular o público ao Estado.

No Dicionário Aurélio, público é definido da seguinte forma:

Relativo, pertencente ou destinado ao povo, à coletividade, ou ao governo de um país. Que é do uso de todos, ou que está aberto ou acessível a quaisquer pessoas: hospital público; concursos públicos. Conhecido de todos; manifesto, notório. Que se realiza em presença de testemunhas, perante pessoas; não secreto: ato público (2009, p. 664).

Com relação ao conceito de privado, o dicionário o define como "não público; particular" (Id., 2009, p. 654-655), portanto como oposto de público.

O vocabulário jurídico apresenta a seguinte etimologia e definição de privado:

Do latim privatus, de privus (próprio, particular, individual), na significação jurídica exprime o sentido de individual ou o que é próprio ou pertinente às pessoas, consideradas, isoladamente, como indivíduos ou como particulares. Opõe-se, assim, ao sentido de público, em que se integra a ideia de pessoas consideradas como uma organização política, e encaradas por seu todo ou pela coletividade que compõem, sem qualquer atenção às suas individualidades (DE PLÁCIDO; SILVA, 2004, p. 1097).

De acordo com as definições anteriores, como "propriedade", privado nos remete ao particular, portanto não é propriedade coletiva e/ou para usufruto de todos. Como "ação", privado se refere a algo que atende aos interesses particulares de determinados indivíduos. Sendo assim, as acepções de privado seguem variações que são restritas ao indivíduo, tanto no sentido de algo que pertence a ele, como no sentido de atender ao interesse particular de indivíduos e/ou de grupos restritos. 
Ao tratar de público e privado, Bobbio destaca a condição de coexistência e de proporcionalidade entre essas duas dimensões, ou seja, a existência do privado pressupõe a existência do seu oposto, o público e vice-versa. Sendo dimensões opostas de uma relação, uma delas predomina sobre a outra. Para Bobbio (1987, p. 14):

\begin{abstract}
Os dois termos de uma dicotomia podem ser definidos um independentemente do outro, ou então apenas um deles é definido e o outro ganha uma definição negativa (a 'paz' como 'não-guerra'). Nesse segundo caso diz-se que o primeiro é o termo forte, o segundo o termo fraco. [...]. Além do mais, pode-se dizer que os dois termos de uma dicotomia condicionam-se reciprocamente, no sentido de que se reclamam continuamente um ao outro: na linguagem jurídica, a escritura pública remete imediatamente por contraste à escritura privada e vice-versa; na linguagem comum, o interesse público determina-se imediatamente em relação e em contraste com o interesse privado e vice-versa. Enfim, no interior do espaço que os dois termos delimitam, a partir do momento em que este espaço é totalmente ocupado (tertium non datur), eles por sua vez se delimitam reciprocamente, no sentido de que a esfera do público chega até onde começa a esfera do privado e vice-versa. Para cada uma das situações a que convêm o uso da dicotomia, as duas respectivas esferas podem ser diversas, cada uma delas ora maior ou menor, ou por um ou por outro dos dois termos. [Grifos nossos].
\end{abstract}

A dicotomia entre público e privado, quando tratada no campo do direito positivo, conforme expõe Bobbio, apresenta uma visão, aparentemente, precisa das fronteiras entre esses dois elementos. Mas se a localizarmos no conjunto das relações sociais, veremos que são mais complexas e muitas vezes são fronteiras tênues ao ponto de se dificultar a identificação e as distinções do que é "público" e do que é "privado".

Nesse sentido, consideramos que existe uma relação antagônica e de coexistência entre "público e privado", conforme mencionado por Bobbio. No entanto, compreendemos que esse antagonismo não é "exato", como a perspectiva do direito expõe, pois ao localizarmos a relação "público-privado" no contexto das relações sociais, notaremos o desenvolvimento de políticas públicas, teoricamente para todos, sob a perspectiva privada. Ou, ainda, segmentos privados, como as empresas, que desenvolvem serviços de interesse público. No decorrer do artigo, veremos que o Instituto Unibanco realiza esses dois movimentos.

Apesar de o Direito Administrativo regulamentar as variações da relação públicoprivada, em serviço público próprio, no caso do serviço prestado pelo Estado stricto sensu e, em serviço público impróprio para as atividades de interesse público desenvolvida pela iniciativa privada, a estrutura rígida do Direito não permite a constante regulamentação das múltiplas formas e tendências que a relação público-privada tem manifestado no atual contexto histórico. Nos limites do Direito Administrativo e no caso específico da educação, serviço público próprio e impróprio são assim definidos:

Qualquer classe de escola, com efeito, promovida pelo Estado ou pelos particulares pode realizar um serviço de interesse público e até um serviço público, ou seja, uma prestação de bens e serviços (neste caso, o serviço educativo) cujo objetivo é o bem da comunidade, e aqui é onde cabe a interpretação equívoca dos termos. Porque o termo serviço público pode ser interpretado de distinta forma, ao menos, em sentido próprio e em sentido impróprio. O sentido próprio de serviço público se costuma entender como uma realidade jurídica assumida pela administração estatal. $O$ segundo, ao contrário, serviço público, porém não assumido pela administração estatal e sim por uma entidade particular (serviço público de gestão privada). (DICIONÁRIO CANÔNICO, 1993, pp. 308-309, verbete: Escola Pública apud ARAUJO, 2005, p. 127).

A ideia de "proporcionalidade" entre "público e privado" nos remete, por exemplo, aos processos de elaboração e efetivação de políticas públicas, pois esses processos são 
repletos de disputas que representam diferentes interesses de classes e/ou grupos sociais, sendo que a proporcionalidade entre a condição pública de ser para todos e a condição privada de atender interesses singulares de indivíduos e grupos específicos dependerá dos embates traçados no conjunto das relações sociais e, especificamente, dos embates inerentes ao desenvolvimento e à efetivação da política pública. A delimitação do público ao Estado stricto sensu e do privado à sociedade civil é uma das maneiras de compreender esses conceitos, conforme a análise de Bobbio $(1987$, p. 17) na citação a seguir:

\begin{abstract}
Com o nascimento da economia política, da qual deriva a diferenciação entre a esfera econômica e a esfera das relações políticas, entendidas as relações econômicas como relações substancialmente de desiguais por efeito da divisão do trabalho mas formalmente iguais no mercado, a dicotomia público/privado volta a se apresentar sob a forma de distinção entre sociedade política (ou de desiguais) e sociedade econômica (ou de iguais), ou do ponto de vista do sujeito característico de ambas, entre a sociedade do citoyen que atende ao interesse público e a sociedade bourgeois que cuida dos próprios interesses privados em concorrência ou em colaboração com outros indivíduos.
\end{abstract}

No sentido atribuído por Bobbio, existe uma dicotomia orgânica entre sociedade política e sociedade econômica (sociedade civil). Já para Gramsci, a separação entre sociedade política e sociedade civil é meramente metodológica, pois organicamente estão relacionadas. Pois é essa visão de indissociabilidade entre sociedade política e sociedade civil a base da definição gramsciana de Estado ${ }^{3}$, definição esta que guia nossas análises sobre a relação público-privada no contexto dos projetos voltados para o Ensino Médio.

Ao considerar a sociedade civil como uma instância de poder tal qual a sociedade política, Gramsci define o Estado como uma expressão orgânica da relação entre ambas. Com base nessa definição, concebemos a relação público-privada como um processo contraditório que permeia a sociedade política e a sociedade civil, sendo que ora predomina a dimensão pública e ora a dimensão privada. A condição legal de representante do interesse público contribui para que o Estado stricto sensu seja alvo de disputas por classes e/ou grupos sociais que buscam legitimar os seus projetos e os seus interesses pela via da legitimidade, da abrangência e do financiamento próprios das políticas públicas. Sendo assim, entendemos que o Estado (sociedade política e sociedade civil) é um campo de disputas e de contradições e é nesse campo que são elaboradas e implementadas as políticas públicas.

Gramsci compreendeu que o Estado moderno demanda por um processo democrático sustentado pelo consenso, pela aprovação/consentimento da sociedade civil, especialmente, por meio do processo de eleições de representantes para o seu governo, por isso, nas sociedades democráticas, a "sociedade civil" elege representantes com a responsabilidade de governá-la e, com isso, se estabelece um "contrato" entre governantes e governados com base no consenso da sociedade (COUTINHO, 2014).

Ainda que o Estado stricto sensu preserve a sua condição coercitiva, a dimensão consensual oriunda da sociedade civil passa a ser fundamental para a conquista, a manutenção e a ampliação do poder do grupo que predomina na sociedade política e que necessita constituir além da dominação, na direção ou na hegemonia social. 
Entendemos que existe uma unidade entre a estrutura e a superestrutura da sociedade e que a configuração dessa unidade é composta por elementos contrários e distintos. Sendo assim, o Estado também é composto por contradições, por isso, ainda que represente predominantemente certos interesses de classes e grupos sociais, sua forma, conteúdo e ações não são absolutamente voltados para a classe que o domina. Um aspecto que expressa o caráter contraditório do Estado encontra-se na sua configuração a partir da articulação da sociedade política com a sociedade civil, sendo que

A ordem sociopolítica, portanto, é construída pela interpenetração dessas duas esferas analiticamente separadas, mas estreitamente relacionadas. A primeira é precisamente o que os liberais clássicos e os neoliberais entendem por Estado: a organização administrativa, jurídica e militar do aparelho governamental, ou o Estado como 'guarda-noturno' e fiador da paz, segurança e ordem. A sociedade civil, porém, é a esfera da liberdade, na qual, nas sociedades modernas (especialmente ocidentais), há uma proliferação de associações secundárias independentes, políticas, econômicas, culturais, educacionais, religiosas ou sociais. É na sociedade civil que grupos e concepções ideológico-culturais, na sua pluralidade e multiplicidade, competem uns com os outros (FONTANA, 2003, p. 116-117).

O conceito de "Estado integral" se relaciona com o conceito de hegemonia, isto é, a direção intelectual, moral, política e cultural que uma determinada classe social busca imprimir como consenso social. Por isso, em Gramsci, o Estado deve ser associado à hegemonia, o que faz com que ele também tenha um "papel educativo" no sentido de buscar o consenso ${ }^{4} \mathrm{da}$ sociedade, só assim a classe que domina o Estado stricto sensu será também a classe dirigente.

Por isso, com base em Gramsci, entendemos que não basta a dominação por meio da coerção para se manter como classe e/ou grupo dominante, mas há necessidade de se ter a direção intelectual, moral, política e cultural da sociedade. Consideramos esse fundamento essencial para entender um dos motivos que leva o empresariado do setor financeiro, por exemplo, por meio do Instituto Unibanco, a produzir um projeto de formação humana para os jovens brasileiros e de gestão para a escola pública. Entendemos que é a busca pela hegemonia o principal motivo que representa a incessante busca pelo fortalecimento do "[...] nexo entre poder e conhecimento e a transformação do bem particular em interesse universal" (FONTANA, 2003, p. 121). Esse processo de constituição da hegemonia, aqui ilustrado pela atuação do Instituto Unibanco, remete nosso olhar para outro conceito gramsciano, o de "intelectual orgânico". Gramsci, ao falar sobre a formação dos intelectuais, menciona a formação do intelectual tradicional e do intelectual orgânico. O primeiro se considera autônomo e independente de grupos sociais. Já o intelectual orgânico é uma categoria presente nas classes e/ou grupos sociais, isto é,

Todo grupo social, nascendo no terreno originário de uma função essencial no mundo da produção econômica, cria para si, ao mesmo tempo, organicamente, uma ou mais camadas de intelectuais que Ihe dão homogeneidade e consciência da própria função, não apenas no campo econômico, mas também no social e político. [...]. Se não todos os empresários, pelo menos uma elite deles deve possuir a capacidade de organizar a sociedade em geral, em todo o seu complexo organismo de serviços, até o organismo estatal, tendo em vista a necessidade de criar as condições mais favoráveis à expansão da própria classe; ou, pelo menos, deve possuir a capacidade de escolher os 'prepostos' (empregados especializados) a quem confiar esta atividade organizativa das relações gerais exteriores à empresa (GRAMSCI, 2004, p. 15-16). 
Consideramos que o Instituto Unibanco, um dos representantes do empresariado brasileiro no processo de intensificação da hegemonia desse grupo social, constitui-se como um dos seus intelectuais orgânicos com o intuito de disseminar a direção política e cultural do empresariado, por meio da educação e da gestão escolar da escola pública. Sendo assim, por intermédio do trabalho dos seus intelectuais, o grupo do empresariado brasileiro, nesse caso, disputa espaços no interior da sociedade política e sociedade civil, especialmente, no contexto escola pública.

Diante do exposto, retomemos a ideia de que a relação público-privada é antagônica. Ainda assim, ela é necessária, especialmente no atual momento histórico em que "público" e "privado" têm aparecido na forma de "parcerias". Tanto que, comumente, encontramos notícias, documentos oficiais, relatórios de organismos internacionais e demais registros que indicam que o poder público e a iniciativa privada se uniram em prol de determinado projeto. Essa organização conjunta entre público e privado passou a ser denominada como Parceria Público-Privada (PPP). No Brasil, por exemplo, as PPPs estão regulamentadas por leis, como a Lei n. 11.079, de 30 de dezembro de 2004, que institui normas gerais para licitação e contratação de parceria público-privada no âmbito da administração pública. A PPP é interpretada como

\begin{abstract}
[...] a reunião de esforços entre o Poder Público e o setor privado para a concretização de objetivos de interesse público, a partir de iniciativas legislativas (termo de parceria), bem como da sua aceitação pela doutrina no âmbito do Direito Público. Cabe ainda, nesta perspectiva, a designação de todas as formas de sociedade que, apesar de não formarem uma nova pessoa jurídica, se organizam entre os setores público e privado, para a consecução dos interesses públicos (DI PIETRO, 2006 apud ADRIÃO, PERONI, 2009, p. 1).
\end{abstract}

Entendemos, ainda, que as PPPs são variações da relação público-privada, normatizadas pelo aparato jurídico. Assim, a sociedade política, representante legal do público, ao estabelecer parceria com o setor privado, articula a condição pública e a estrutura do aparelho estatal aos interesses privados, assim como o Estado stricto sensu se desvincula de certas responsabilidades comumente atribuídas para ele, por isso "a ideia das parcerias, portanto, parece agir como um mecanismo útil, não apenas por colocar diferentes atores juntos e, por isso, diferentes grupos e diferentes tipos de conhecimento, mas por intermediar, mais do que mitigar ou mediar, a privatização na e da educação (ROBERTSON; VERGER, 2012, p.1141). Por isso, as PPPs ressaltam as contradições entre público e privado e, apesar dos contratos, dos acordos e das normatizações, nas PPPs sempre haverá a predominância de uma das dimensões. As pesquisas da área da educação têm demonstrado que a dimensão predominante é a de perspectiva privada, especialmente a partir dos múltiplos arranjos e das formas de parcerias. Nesse sentido, Robertson e Verger (2012) nos chamam a atenção para o desenvolvimento de uma verdadeira "indústria especializada" em Parcerias Público-Privadas na Educação (PPPEs).

Esse predomínio da dimensão privada nos processos de parcerias entre a esfera pública e a esfera privada tem relação com o caráter mercadológico transposto à 
organização e ação do Estado stricto sensu, gerando no seu contexto uma espécie de quase-mercado, isto é,

A prática da competitividade e da implantação da lógica de mercado orientam a agenda política do estado e, simultaneamente, são usados para legitimar essa mesma agenda, tanto a nível externo como interno. A legitimação externa e direcionada em sentido ascendente e para o exterior em relação as organizações supranacionais e regionais, assim em relação a empresas transnacionais que tem interesse no desempenho econômico global do estado, na estabilidade política, nas práticas do mercado de trabalho, nas relações de comércio/intercâmbio internacional, etc. A legitimação interna e direcionada para a sociedade civil e para o capital nacional e centra-se em assuntos como a produtividade econômica, a estabilidade social e os direitos da cidadania. Em conjunto, a reestruturação global, regional, nacional e local mudaram a natureza e o âmbito da legitimação e a maneira como este se constitui problema para o estado (ROBERTSON; DALE, 2001, p. 118).

No Brasil, as diversas instituições que representam o empresariado brasileiro atuam na direção de legitimarem, por meio de políticas públicas, projetos considerados essenciais para os ganhos de produtividade empresarial. Portanto, o empresariado, ao transferir seus projetos às políticas públicas, transformam-nas em ações estatais de perspectiva e com resultados restritos ao grupo de interesse, isto é, resultados privados, portanto, negam o sentido público de ser para todos. Sobre essa questão, Peroni (2012, p. 26) assevera que

[...] verificamos que, no Brasil, a concepção de quase-mercado na educação tem sido introduzida principalmente pela interlocução direta dos empresários com os governos, como no movimento Todos pela Educação, ou por parcerias em todos os níveis, desde o nacional até o escolar, como, por exemplo, com o Instituto Ayrton Senna ou o Instituto Unibanco, com o Programa Jovem do Futuro enfim, inúmeras entidades privadas, que têm o mercado como parâmetro de qualidade e a simpatia da sociedade, por se apresentarem como instituições filantrópicas, sem fins lucrativos, que querem o "bem" da educação.

Diante do exposto, consideramos como pressuposto fundamental que, das parcerias e dos acordos estabelecidos entre MEC, Secretarias de Estado da Educação e Instituto Unibanco, que resultaram no ProEMI/JF, as contradições entre público e privado são ressaltadas no processo de formação humana e de gestão escolar. A incorporação de um projeto privado no contexto de uma política pública não significa que esse projeto tenha um interesse público no sentido de atender a todos, de ser para todos. A estrutura é pública, porque é vinculada ao Estado stricto sensu, mas o resultado social do desenvolvimento do PJF como política pública é um resultado que não contempla a todos, ou seja, é um resultado de interesse privado, pois tem como finalidade a seleção dos considerados "melhores" jovens e das escolas reconhecidas como "melhores" e, com isso, o projeto almeja atingir o objetivo principal que diz respeito à intensificação do processo de direção política e cultura do grupo do empresariado no contexto da sociedade brasileira 


\section{A relação público-privada no contexto do ProEMI e Do ProEMI/PJF}

Compreendemos que as intervenções do empresariado brasileiro na educação pública estão relacionadas com os seus interesses de ampliar e aprofundar o domínio cultural e a direção política no contexto da sociedade civil; formar a mão de obra adequada aos seus interesses; disputar recursos públicos para efetivar os seus projetos de formação humana/educação. Com base nos pressupostos teóricos gramscianos anunciados anteriormente, analisamos os movimentos de disputas entre o público o privado no curso das políticas curriculares para o Ensino Médio. Nosso ponto de partida é o contexto de disputas e embates presente nos governos Lula da Silva (2003-2011) e Dilma Rousseff (2011-2016). Apresentamos, em especial, os embates entre segmentos do empresariado brasileiro e intelectuais ligados às instituições científicas e aos movimentos de defesa da escola pública nos processos de definição de algumas políticas para educação, conforme sistematizamos no quadro a seguir:

Quadro 1 - Políticas educacionais em disputas nos governos Lula da Silva e Dilma Rousseff

\begin{tabular}{|l|l|}
\hline Governo Lula da Silva (2003-2011) & Governo Dilma Rousseff (2003-2011) \\
\hline Política & Políticas \\
Programa de Desenvolvimento da Edu- & Programa Ensino Médio Inovador - \\
cação - MEC; & ProEMI - MEC; \\
Perspectiva predominante: & Pacto Nacional de Fortalecimento do \\
Todos pela Educação por intermédio & Ensino Médio - MEC \\
do documento "Dez causas e 26 com- & Perspectiva predominante: \\
promissos"; & Participação de intelectuais vinculados \\
X & às instituições científicas e aos movi- \\
Política & mentos de defesa da escola pública; \\
Ensino Médio Integral - MEC & X \\
Perspectiva predominante & Política \\
Intelectuais ligados às instituições & Projeto Jovem de Futuro do Instituto \\
científicas e aos movimentos de defesa & Unibanco - inserido no catálogo de \\
da escola pública formularam o Ensino & tecnologias educacionais do MEC; \\
Médio Integrado. & ProEMI vinculado ao PJF - ProEMI/PJF \\
& - acordo de cooperação técnica entre \\
& MEC e Instituto Unibanco; \\
& Perspectiva predominante \\
Empresariado brasileiro por meio do \\
\hline
\end{tabular}

Fonte: Elaborado pelas autoras. 
Do conjunto de políticas que contaram com a expressiva participação do empresariado brasileiro, conforme mencionado no quadro anterior, destacamos a parceria do MEC com o Instituto Unibanco, criando, entre 2011 e 2012, o ProEMI/JF. De acordo com publicação da extinta Secretaria de Assuntos Estratégicos (SAE), MEC e IU, assinaram um acordo

[...] de Cooperação Técnica para o desenvolvimento de estudos, projetos, pesquisas e avaliações em conjunto. O foco das ações que serão desenvolvidas por meio do acordo será a área de educação, com ênfase nos jovens do Ensino Médio público. [...].

Pelo acordo de Cooperação Técnica, que estará vigente até 2013, o Instituto Unibanco terá como atribuições disponibilizar dados necessários à execução dos trabalhos e indicar um responsável técnico para acompanhar as atividades previstas. Já a SAE terá a responsabilidade de dar apoio técnico e metodológico à elaboração de pesquisas desenvolvidas pelo Grupo de Trabalho de Gestão de Conhecimento do Instituto Unibanco e colaborar nas avaliações de impacto das experiências (projetos) conduzidas pelo Instituto Unibanco, entre outras funções (BRASIL. SAE, 2011, s/p).

O acordo confirmado em 2011 ratificou uma prática de intervenção do IU nas políticas para o Ensino Médio, pois o Instituto, desde a criação do Projeto Jovem de Futuro, busca parcerias com estados e governo federal para viabilizar a sua proposta de formação dos jovens brasileiros entre as parcerias anteriores ao Acordo, conforme anunciou a publicação da SAE, estava "[...] a avaliação de impacto do primeiro ciclo de três anos do Projeto Jovem de Futuro nos estados de Minas Gerais e Rio Grande do Sul, conduzida pelo subsecretário da SAE, Ricardo Paes de Barros" (BRASIL. SAE, 2011, s/p).

Com base na participação do empresariado e dos intelectuais da educação na elaboração das políticas educacionais, nos governos de Lula da Silva e Dilma Rousseff, notamos proposições "[...] predominantemente representantes de perspectivas do setor privado e outras predominantemente representantes da perspectiva pública no sentido de ser para todos", como o ProEMI/PJF e ProEMI, respectivamente.

A análise de Dourado (2007, p. 928) sobre as contradições de perspectivas nas políticas públicas nos governos Lula da Silva também pode ser estendida ao governo Dilma Rousseff, pois os dois governos retrataram

[...] um cenário ambíguo, no qual um conjunto de programas parece avançar na direção de políticas com caráter inclusivo e democrático, enquanto, de outro lado, prevalece a ênfase gerencial, com forte viés tecnicista e produtivista, que vislumbra nos testes estandardizados a naturalização do cenário desigual em que se dá a educação brasileira. Os programas federais de educação básica, atravessados por concepções distintas e até antagônicas, realçam o cenário contraditório das ações governamentais.

As disputas entre segmentos representantes dos interesses privados e públicos revelam um "cenário ambíguo" e de "concepções distintas e antagônicas", também no caso da elaboração do ProEMI, conforme discutiremos na próxima subseção. 


\section{A relação público-privada no contexto do ProEMl}

No primeiro mandato de Lula da Silva (2003-2007), os fundamentos para o Ensino Médio foram construídos a partir da ideia de formação humana integral politécnica e estão presentes nos documentos orientadores do Ensino Médio Integrado ${ }^{5}$. Esses fundamentos estão registrados nos documentos "Políticas para o Ensino MédioRealizações 2003 e perspectivas 2004"; "Ensino Médio Integrado: uma perspectiva abrangente na política pública educacional - versão preliminar" (sem publicação oficial). Tais documentos sugerem a constituição de uma política nacional para o Ensino Médio. A origem do ProEMI é decorrência desse processo (SILVA, 2016).

Notamos que, no primeiro mandato de Lula da Silva, havia um movimento na elaboração das políticas curriculares para o Ensino Médio de retirada do modelo de competências que trazia uma vertente de matiz empresarial e economicista (SILVA, 2008). Em substituição a esse modelo, avançou a ideia de formação politécnica e escola unitária de acordo com os princípios gramscianos, ao remeter à ideia de trabalho como princípio educativo. Essa perspectiva estava, também, nos fundamentos conceituais que orientaram o Programa Ensino Médio Inovador.

Ainda que o ProEMI tenha como vertente esses fundamentos, suas versões iniciais guardavam elementos das políticas curriculares dos anos de 1990, em que o modelo de competências predominava. Em 2009, o Programa Ensino Médio Inovador foi criado pela Portaria n. 971, de 2009, como possibilidade para enfrentar problemáticas referentes ao ingresso e à permanência, ao abandono, à reprovação no Ensino Médio. Durante o desenvolvimento do ProEMI, seus documentos orientadores passaram por quatro versões, publicadas nos anos de 2009, 2011, 2013 e 2014. Na sua versão mais apurada, de 2014, o ProEMI é definido como um instrumento de indução ao redesenho curricular sustentado pelas novas Diretrizes Curriculares Nacionais Ensino Médio (DCNEM), aprovadas em 2012.

O Parecer CNE/CEB 05/2011, que antecedeu à Resolução n. 2, de 30 de janeiro de 2012 (DCNEM), afirma que as "Diretrizes orientam-se no sentido do oferecimento de uma formação humana integral, evitando a orientação limitada da preparação para o vestibular [...]" (BRASIL. CNE.CEB. 2011, p. 12). Entendemos, portanto, que tal perspectiva anunciada pelas DCNEM e pelo referido parecer se aproxima de uma perspectiva de interesse público, pois não objetiva a formação pragmática e voltada ao mercado de trabalho e tampouco a formação enciclopédica, que reduz o Ensino Médio a um curso meramente preparatório para o vestibular.

Para sintetizar os movimentos das perspectivas público-privadas no âmbito dos documentos do ProEMI, organizarmos o quadro a seguir: 
Quadro 2 - Concepções de formação humana nos documentos orientadores do ProEMI

\begin{tabular}{|l|l|}
\hline $\begin{array}{l}\text { Versão do Documento } \\
\text { Orientador }\end{array}$ & Concepção de formação humana \\
\hline 2009 & $\begin{array}{l}\text { Duas perspectivas: Formação humana integral com } \\
\text { base nos documentos que antecederam a elabo- } \\
\text { ração do ProEMI; com base nas DCNEM da Reso- } \\
\text { lução CNE/CEB n.3, de } 26 \text { de junho de 1998, for- } \\
\text { mação embasada em competências e habilidades. }\end{array}$ \\
\hline 2011 & $\begin{array}{l}\text { Sem referência à formação humana integral; } \\
\text { Predomínio das DCNEM de 1998, portanto for- } \\
\text { mação por competências, como orientadora do } \\
\text { currículo. }\end{array}$ \\
\hline $2013 / 2014$ & $\begin{array}{l}\text { Em 2012, com a aprovação das novas DCNEM } \\
\text { e retomada dos princípios da formação integral } \\
\text { de viés politécnico e do eixo curricular trabalho- } \\
\text { ciência-cultura-tecnologia, tais fundamentos foram } \\
\text { incorporados pelas últimas versões do documento } \\
\text { orientador do ProEMI. }\end{array}$ \\
\hline
\end{tabular}

Fonte: Elaborado pelas autoras com base nos documentos orientadores do PRoEMI (2009, 2011, 2013 e 2014)

Notamos, portanto, que o conteúdo da primeira versão do documento do ProEMI foi uma das contradições presentes na transição de uma política curricular (modelo de competências) para outra política que sugeria a formação humana integral. A primeira como projeto de interesses privados, em especial, do empresariado brasileiro; a segunda como proposta dos intelectuais, que se posicionavam a favor da escola pública e de uma formação integral e emancipatória. O ProEMI se fortaleceu como política que se aproximava da segunda alternativa mencionada anteriormente, na medida que se agregou ao movimento e aos fundamentos das DCNEM aprovadas em 2012. Naquele momento, tal movimento representava o avanço da perspectiva pública no conjunto das políticas curriculares para o Ensino Médio, com isso ocorreu uma retração da perspectiva privada no conteúdo das DCNEM. Vale mencionar, ainda, que desde o início o ProEMI sustentava princípios e práticas de gestão democrática, haja vista que as escolas deveriam planejar, realizar e acompanhar coletivamente os projetos de redesenho curricular.

Se em uma direção, no campo das políticas curriculares para o Ensino Médio, avançou a perspectiva mencionada, em 2012, diante do tensionamento entre público e privado no contexto da sociedade política, também ganhou espaço o projeto privado do empresariado brasileiro, pois o acordo entre MEC e Instituto Unibanco promoveu o imbricamento do PJF com o ProEMI, criando o ProEMI/PJF como antítese à perspectiva de formação humana integral presente nas últimas versões do ProEMI. 


\section{A relação público-privada no contexto do ProEMI/JF: antítese à concepção de formação humana integral}

O Instituto Unibanco faz parte das instituições de atuação social do conglomerado financeiro Itaú-Unibanco. No decorrer do seu desenvolvimento, o IU direcionou suas ações para projetos de formação dos jovens e se especializou nas questões referentes ao Ensino Médio. Em 2006, o IU publicou um conjunto de intencionalidades e estabeleceu novas parcerias conforme explicita o trecho do seu relatório:

[...] associou-se ao Compromisso Pela Educação, movimento nacional que uniu vários segmentos
da sociedade civil para garantir, até setembro de 2022, ano do bicentenário da Independência do
Brasil, o pleno acesso de crianças e jovens a uma educação de qualidade. Em reconhecimento a esse
conjunto de participações sociais, as atividades de cidadania empresarial promovidas pelo Instituto
Unibanco passaram a figurar no site Em Boa Companhia, da Bovespa (Bolsa de Valores de São Paulo),
que divulga, para investidores e à opinião pública, as melhores práticas de empresas socialmente
responsáveis. A instituição recebeu ainda valorizações externas como o Prêmio Ambiental Von
Martius, que distinguiu o projeto Natureza Jovem - Protetores da Serra, desenvolvido em parceria
com a Associação Caatinga, na região de Crateús, no Ceará. A comunicação da instituição com seus
diversos públicos de relacionamento também foi reconhecida nesse período. A Aberje (Associação
Brasileira de Comunicação Empresarial) concedeu ao boletim eletrônico Panorama Social, que circula
a cada dois meses entre parceiros e entidades do terceiro setor, o prêmio regional na categoria
Newsletter Digital (INSTITUTO UNIBANCO, 2006, p. 11).

De acordo com a citação anterior, as intervenções do conglomerado Itaú-Unibanco nas áreas sociais são estratégias para disseminar a ideia de "humanização da empresa" e de que há um compromisso e/ou "responsabilidade social" por parte de grupo financeiro. Tais estratégias servem para vender a imagem da empresa e agregar valor à sua marca nas negociações comerciais como da bolsa de valores. Para tanto, o IU explica suas ações como:

Longe da filantropia e sem assumir papéis que substituam ou se confundam com a ação do Estado,
concentra sua ação no estabelecimento de Parcerias Público-Privadas que contribuam para melhorar
a ação dos governos em suas políticas sociais e principalmente a educação. [...] Assim como no
mundo dos negócios, investimento social pressupõe retorno. A diferença é que o lucro dá lugar
aos benefícios para a sociedade como resultado esperado do investimento. É uma decorrência,
portanto, a necessidade de contar com meios de avaliar, mensurar e certificar esses ganhos. [...].
Transferir a expertise empresarial de transformar conhecimento em técnica e ter a técnica a serviço
da produção de resultados sociais é o que de melhor o empresariado pode oferecer como apoio
(INSTITUTO UNIBANCO, 2009, p. 16).

Consideramos que, além desses objetivos, o IU, em conjunto com o empresariado brasileiro, ao interferirem na educação pública por intermédio do Todos pela Educaçãó, almejam a intensificação da direção política e cultural da sociedade, nos termos gramscianos, almejam o aprofundamento da hegemonia do seu projeto educacional, assim como veremos na discussão sobre o PJF. No final de 2006, com base nas atividades do Centro de Estudos 7 do Instituto Unibanco, surgiu o "Projeto Jovem de Futuro Qualidade Total no Ensino Médio" direcionado, inicialmente, para escolas públicas de São Paulo e que eram atendidas pelo Centro. O PJF associa, desde sua origem, o melhor desempenho dos alunos em avaliações internas e/ou em grande escala, com qualidade educacional e com uma gestão escolar de e para resultados (INSTITUTO UNIBANCO, 2012). Ao analisar o PJF, Caetano (2015, p. 96) faz a seguinte reflexão: 
As mudanças que vêm ocorrendo na gestão da educação nos últimos anos mostram que essas não são apenas alterações técnicas. Há introdução de uma nova cultura com uma nova linguagem, um novo conjunto de incentivos e um novo conjunto de papéis, posições e identidades. Dessa forma, modificase, consequentemente, o significado da educação, alterando o significado de ser um professor, aluno, pai, formando uma visão hegemônica mercantil. Não são simplesmente os serviços de educação e de ensino que estão sujeitos a formas de privatização: a própria política de educação - por meio de assessorias, consultorias, pesquisas, avaliações e redes de influências. Estamos assistindo realmente à privatização da dimensão política da educação, dimensão da "coisa pública" [...].

A privatização da dimensão política da educação, conforme mencionada pela autora, é observada no conteúdo, na forma e na efetivação do PJF, pois as PPPs, estabelecidas pelo IU com o executivo federal, estaduais e municipais, viabilizaram a realização do projeto privado como política pública e com financiamento público. Para Peroni (2013, p. 28), as PPPs

[...] que inicialmente estavam no âmbito estadual e municipal atualmente também ocorrem com a Presidência da República para a elaboração de políticas nacionais de educação. Destacamos interlocução dos Institutos Unibanco e Ayrton Senna com o governo federal, mais especificamente a Secretaria de Assuntos Estratégicos da Presidência da República, para que seus programas sejam transformados em políticas de alcance nacional [...]. [Grifos nossos].

Ao estabelecer o acordo de cooperação com o IU, o Estado (stricto sensu), legitima o PJF como política pública e reafirma seu papel de Estado educador, no sentido gramsciano, pois auxilia na implementação de um

[...] projeto social amplo, de âmbito econômico e de direção política, faz parte da correlação de forças que tomam a educação e o currículo como campo de disputas. A sua proposta educativa, implementada junto às escolas, tem uma concepção de educação voltada à formação e à inserção das novas gerações no mercado de trabalho, atribuindo a conclusão do Ensino Médio às condições de empregabilidade (MONTEIRO, 2013, p. 284).

Identificamos nos Relatórios de Atividades do IU que o PJF parte da lógica meritocrática8 para elaborar a sua concepção de formação humana e de gestão escolar, por isso trabalha com a ideia de classificação, de premiação dos melhores e de punição (corte de recursos) para as escolas que não atingirem as metas do projeto e, com isso, acentua também a exclusão dos alunos com baixo desempenho escolar, configurando, claramente, uma perspectiva gerencialista de gestão. O ProEMI e o ProEMI/JF, portanto, são duas propostas distintas para o Ensino Médio das escolas públicas. As contradições entre propostas educacionais também estão relacionadas com os movimentos do mundo do trabalho, pois "[...] quaisquer que sejam as causas primeiras e ou aparentes, sempre há um processo ao longo do qual tende a se produzir um ajuste entre o que a escola dá e o que a produção pede" (ENGUITA, 1993, p. 231). Nas questões que analisamos, notamos que existem diversas tentativas do empresariado no sentido de ajustar a educação às demandas da produção. Desta forma, as contradições entre público e privado se aprofundam na educação pública, pois é

[...] impossível de concretizar um ajuste perfeito, traduz-se num campo de mediação representado por processos educacionais formais e não formais, nos quais a tensão e as disputas sociais prevalecem frente às tentativas de homogeneização e controle do quê, como e para quê desses processos. De toda forma, as práticas reformistas que envolvem a educação, especialmente em momentos de reordenamento do sistema do capital, visam tornar predominantes determinadas interpretações e propostas de articulação entre produção e escola (CÊA; SANDRI, 2008, p. 79). 
Compreendemos que o IU, intelectual orgânico do empresariado brasileiro para assuntos referentes ao Ensino Médio, exerceu um importante papel no sentido de "ajustar" o ProEMI aos seus interesses, gerando, com isso, a sua antítese, o ProEMI/PJF. Para tanto, contou com a legitimação do Estado (stricto sensu) ao transformar o projeto de perspectiva privada em política pública. Com isso, "[...] o Estado assume cada vez mais um papel educador, na medida em que passa a propor a condução de amplos setores da população a uma reforma intelectual e moral adequada ao projeto de sociabilidade dominante e dirigente" (NEVES, 2005, p. 16).

\section{Decorrências do imbricamento entre ProEMI e PJF}

Os principais fundamentos do PJF estão estruturados na ideologia da meritocracia, na teoria do capital humano e na gestão de tipo gerencial. São perspectivas que servem de estratégia teórico-metodológica para a implementação do Projeto e fazem parte do processo de intensificação da hegemonia do empresariado no contexto social, sendo que a escola pública é considerada pelo empresariado um dos caminhos para o processo de ampliação da sua direção política.

A estratégia teórico-prática do IU para adentrar a escola pública e abarcar a totalidade da organização do trabalho pedagógico é identificada por meio do reconhecimento do PJF como uma tecnologia de gestão escolar, reconhecimento este que atesta que esse projeto tem condições de ser desenvolvido por qualquer escola pública brasileira como um instrumento de gestão escolar. Ao ser desenvolvido pela escola pública como uma ferramenta de gestão escolar, o PJF deixa de se restringir ao Ensino Médio, pois tem o potencial de se instituir como uma perspectiva de gestão escolar para toda a escola, abarcando outras etapas de Educação Básica e modalidades ofertadas pela escola. Com isso, dissemina seus encaminhamentos teórico-práticos para o currículo escolar, para as formas de avaliação, para as metodologias de ensino e processos de aprendizagem, para a participação da comunidade escolar e, ainda, durante o seu processo de implementação altera a importância do Conselho Escolar, uma vez que cria uma instância acima dele, o Grupo Gestor responsável pelo monitoramento e pela implementação do projeto.

Tais estratégias teórico-práticas do ProEMI/JF definem a concepção de formação para os jovens do Ensino Médio e de gestão para escola pública, conforme constatações apresentadas a seguir:

a) Ideologia da meritocracia como diretriz da formação dos "jovens de futuro":

A ideologia da meritocracia é orientação teórica essencial da proposta do IU, tanto que o próprio título do seu projeto estimula a configuração de uma hierarquia meritocrática entre "jovem de futuro" e "jovem sem futuro". Logo, essa proposta incentiva 
a naturalização da ideia de que alguns jovens terão futuro, enquanto que outros não. Nesse sentido, indagamos: qual é o parâmetro que o ProEMI/JF utiliza para identificar o "jovem de futuro"? Com base na análise do projeto, compreendemos que o parâmetro utilizado parte da compreensão de que a capacidade de cada jovem em se esforçar para melhorar as suas competências em Língua Portuguesa e Matemática e a capacidade de aprender comportamentos gerais demandados pelo mercado de trabalho são critérios para definir o "jovem de futuro" e o "jovem sem futuro". Tais parâmetros se coadunam com a estratégia teórico-prática da ideologia da meritocracia e da teoria do capital humano;

b) Teoria do capital humano como estratégia para transformar os jovens em merecedores de um futuro: os Relatórios de Atividades do IU evidenciaram, desde a origem do PJF e, a partir de 2012, o ProEMI/JF, que a educação do jovem é considerada importante elemento de competitividade entre os países e as empresas, assim como é considerada pelo IU o principal mecanismo para a ascensão econômica e a social dos indivíduos. Com base nesses argumentos, o ProEMI/JF tem incentivado os estudantes a não abandonarem a escola, para tanto, busca convencê-los que basta a educação para atingirem a ascensão social e econômica. Uma estratégia para atribuir veracidade aos seus argumentos é a de deslocar funcionários do Conglomerado Itaú Unibanco para desenvolverem trabalho voluntário, a fim de servirem de exemplos de pessoas bem-sucedidas.

Meritocracia e Teoria do Capital Humano são noções que associam a condição econômica do indivíduo à sua capacidade de ser protagonista do seu próprio destino (protagonismo), o que envolve a capacidade de encontrar soluções para a sua situação financeira (empreendedorismo) e de agregar ao seu "capital humano" um rol de competências capaz de torná-lo empregável nos mais diversos postos de trabalho que venham a ser ofertados pelo mercado de trabalho (empregabilidade). Portanto, as capacidades de ser protagonista, empreendedor e empregável também são condições para se definirem quem será o "jovem de futuro" e o "jovem sem futuro". No caso analisado, a relação público-privada tem se manifestado, assim, a partir da forma-conteúdo oriunda do imbricamento entre ProEMI e PJF, originando uma perspectiva privada que se sobrepõe à dimensão pública de educação no Ensino Médio. Essa forma-conteúdo é proporcionada devido ao poder econômico advindo do empresariado e as aproximações do Estado stricto sensu do mercado, criando para a sociedade política uma perspectiva de "quase-mercado". No caso do IU, uma das instituições representantes do maior conglomerado financeiro da América Latina, este se vale do seu poder econômico para exercer influências no âmbito da sociedade política e da educação pública. Tal situação, aliada à sua ação no âmbito do Estado, o leva a ser tratado como uma instituição que, no contexto empresarial e de alguns governos, passa a ser considerada referência nas questões sobre Ensino Médio, a ponto de ignorar a normatização posta nas Diretrizes Curriculares exaradas pelo Conselho Nacional de Educação, substituindo a perspectiva de formação humana integral ali definida por outra, de vertente meritocrática, economicista e empresarial. 


\section{Considerações Finais}

Entendemos que os dados e as análises desenvolvidas constroem evidências necessárias para comprovarmos a nossa hipótese de que o ProEMI/JF ganha formalidade por meio das PPPs entre MEC-IU e SEDUCs-IU. Essa relação entre uma política pública e um projeto privado dificulta a percepção das contradições entre público e privado, dando a impressão de que a lógica privada também é para o "bem-comum". Esse é o principal motivo que leva o IU a procurar o vínculo com a política pública, como forma de legitimar e tornar a sua proposta consensual no contexto social, em especial, na escola pública e por meio dela.

O setor empresarial se apropria da condição de financiamento e de abrangência da política pública nacional para disseminar a sua proposta de educação que, com isso, intensifica a sua legitimidade; a ideia de que o ProEMI/JF é uma ação para todos passa a ser desmistificada com base na sua principal orientação teórico-metodológica, a ideologia da meritocracia. Essa ideologia, ao servir de fundamento para a formação dos jovens e para a gestão escolar, estimula a classificação e a premiação das escolas e dos estudantes considerados melhores. Por outro lado, exclui jovens e escolas identificadas como incapazes de atingir as metas estipuladas por essa política. Desta forma, o ProEMI/ JF minimiza a dimensão pública em detrimento do predomínio da perspectiva privada. Esta perspectiva conta também com estratégicas teórico-práticas, como a teoria do capital humano e a concepção de gestão escolar traduzida na "Gestão Escolar para Resultados", as quais intensificam a hegemonia do empresariado no contexto do Ensino Médio. A perspectiva privada sofre tensões por parte de intelectuais e movimentos ligados à defesa da escola pública, com a intenção de evidenciarem, no contexto das políticas públicas, concepções de educação que percorrem o efetivo sentido do público de "ser para todos", como são os casos das concepções de formação humana integral e de gestão escolar democrática. No caso do ProEMI/JF, ainda que o Estado stricto sensu tenha contribuído com a intensificação da hegemonia do empresariado no contexto social, é um espaço de disputas entre os diferentes grupos e classe sociais.

Consideramos também que o grande obstáculo que o IU encontra para viabilizar a sua proposta está na própria natureza do seu projeto, que tem como origem a empresa privada. O fato de não considerar a escola pública como referência nos indica que o ProEMI/JF encontraria dificuldades para se efetivar, pois, por mais próximos que possam estar os setores públicos e privados por meio das PPPs, essa proximidade não elimina as contradições que fazem parte da relação social que constitui a condição pública e a condição privada, ao contrário, essas PPPs aprofundam as contradições entre essas dimensões, uma vez que uma tende a prevalecer, enquanto que a outra dimensão é minimizada.

O IU, por meio do PJF, contribui para o desenvolvimento de novas formas da relação público-privada, uma vez que assume o papel de uma instituição produtora de conhecimento 
para políticas educacionais. Exerce, dessa forma, no conjunto das organizações empresariais voltadas para a intervenção na escola pública, o papel de intelectual orgânico do empresariado para as questões de Ensino Médio. Para isso, desenvolve um modus operandi que tem como principal objetivo atender aos interesses do empresariado no processo de intensificação da sua hegemonia no contexto social pela via da educação pública.

\section{Referências}

ADRIÃO, T.; PERONI, V. M. V. A educação pública e sua relação com o setor privado: implicações para a democracia educacional. Revista Retratos da Escola, Brasília-DF, v.3, n. 4, p. 107-116, 2009. Disponível em: <http://www.esforce.org.br/index.php/semestral/ article/view/105/294 f>. Acesso em: 05 de out. 2018

ARAÚJO, J. C. S. O privado e público na história da educação brasileira: da ambivalência ao intercâmbio. In: LOMBARDI, J. C.; JACOMELI, M. R. M.; SILVA, T. M. T. da (Orgs.). 0 público e o privado na história da educação brasileira: concepções e práticas educativas. Campinas, SP: Autores Associados; Histedbr; Unisal, 2005. p. 125-143.

BARBOSA, L. Igualdade e meritocracia: ética do desempenho nas sociedades modernas. Reimpressão. Rio de Janeiro: FGV, 2006. p. 13-103.

BOBBIO, N. Estado, Governo, Sociedade: para uma teoria geral da política. $14^{a}$ ed. Rio de Janeiro: Paz e Terra, 1987. p. 9-31.

BRASIL.CNE.CEB. Parecer n. 15, de $1^{\circ}$ de junho de 1998. Brasília, DF: CNE, CEB, 1998. Disponível em: <http://portal.mec.gov.br/cne/arquivos/pdf/1998/pceb015_98.pdf>. Acesso em 2 de nov. de 2018.

Resolução n.3, de 26 de junho, 1998. Institui as Diretrizes Curriculares Nacionais para o Ensino Médio. Brasília, DF: CNE, CEB, 1998. Disponível em: <http://portal.mec.gov.br/cne/ arquivos/pdf/rceb03_98.pdf>. Acesso em 2 de nov. 2018.

Parecer n. 11, de 30 de junho de 2009. Proposta de experiência curricular inovadora do Ensino Médio. Brasília, DF: CNE, CEB, 2009a. Disponível em: < http://pactoensinomedio.mec. gov.br/images/pdf/parecer_11_30062 009.pdf>. Acesso em 02 nov. 2018.

MEC. SAE. Documento Reestruturação e expansão do Ensino Médio no Brasil. Brasília, DF: MEC, SAE, 2008. (Documento de uso restrito).

.SEB. Parâmetros Curriculares Nacionais Ensino Médio. Brasília, DF: MEC, SEB, 2000. Disponível em: <http://portal.mec.gov.br/seb/arquivos/pdf/blegais.pdf>. Acesso em 30 out 2018.

.CNE. Parecer n. 05, de 4 de abril de 2011. Diretrizes Curriculares Nacionais para o Ensino Médio. Brasília, DF: CNE, CEB, 2011. Disponível em: < http://pactoensinomedio. mec. gov.br/images/pdf/pceb005_11.pdf>. Acesso em 30 de out. 2018.

Resolução n. 2, de 30 de janeiro de 2012. Define Diretrizes Curriculares Nacionais para o Ensino Médio. Brasília, DF: CNE, CEB, 2012. Disponível em: < http://pactoensinomedio. mec.gov.br/images/pdf/resolucao_ceb_002_30012012.pdf>. Acesso em 30 out. 2018 
MEC.SEB. Programa ensino médio inovador: documento orientador (2009; 2011; 2013; 2014). Brasília, DF: MEC, SEB. 2014. Disponível em: .<http://portal.mec.gov.br/ dmdocuments/documento_orientador.pdf>. Acesso em 17 de out de 2018.

. Guia de tecnologias educacionais (2011-2012). Brasília, DF: MEC.SEB, 2011. Disponível em: <http://portaldoprofessor.mec.gov.br/storage/materiais/0000016303.pdf>. Acesso em 17 out. 2018.

CAETANO, M. R. Ensino Médio no Brasil e a privatização do público: o caso do Instituto Unibanco. Revista Universidade e Sociedade. Brasília, DF: ANDES-SN, agosto de 2015. Disponível em: < http://portal.andes.org.br/imprensa/publicacoes/imp-pub-1392300137.pdf>. Acesso em 10 out. 2018.

CÊA, G. S. dos S.; SANDRI, S. Formação geral e mundo do trabalho: horizontes em disputa. In: Currículo sem Fronteiras, v.8, n.1, p.76-93, Jan/Jun 2008. Disponível em: <http://www. curriculosemfronteiras.org/vol8isslarticles/cea_sandri.pdf>. Acesso em: 02 de nov. 2018.

COUTINHO, C. N. O Estado brasileiro: gênese, crise, alternativas. In: LIMA, J. C. F.; NEVES, L. M. W. (Orgs.). Fundamentos da educação escolar no Brasil contemporâneo. Rio de Janeiro: Editora Fiocruz, 2006. p. 173-200.

. Gramsci: um estudo sobre o seu pensamento político. $5^{a}$ ed. Rio de Janeiro: Civilização Brasileira, 2014.

DE PLÁCIDO; S. Vocabulário jurídico. São Paulo: Forense, 2004.

DOURADO, L. F. Políticas de gestão da educação básica no Brasil: limites e perspectivas. Revista Educação e Sociedade, vol. 28, Campinas, SP, n. 100, p. 921-946, out., 2007.

ENGUITA, M. F. Trabalho, Escola e Ideologia: Marx e a crítica da educação. Porto Alegre: Artes Médicas, 1993.

FONTANA, B. Hegemonia e nova ordem mundial. In: COUTINHO, C. N.; TEIXEIRA, A. de P. (Orgs.). Ler Gramsci, entender a realidade. Rio de Janeiro: Civilização Brasileira, 2003, p. 113125.

GRAMSCI, A. Cadernos do Cárcere, Vol 2. Rio de Janeiro: Civilização Brasileira, 2004.

INSTITUTO UNIBANCO. Metodologia Jovem de Futuro. São Paulo: Instituto Unibanco, 2013.

Manual de implementação. São Paulo: Instituto Unibanco, 2012.

. Relatório de Atividades. São Paulo: Instituto Unibanco, 2006. Disponível em: <http:// www.institutounibanco.org.br/wp-content/uploads/2013/09/rel_atividades_IU__2006.pdf>. Acesso em 10 out. 2018.

. Relatório de Atividades. São Paulo: Instituto Unibanco, 2007. Disponível em: <http:// www.institutounibanco.org.br/wpcontent/uploads/2013/09/rel_atividades_IU_2007.pdf>. Acesso em 10 out. 2018.

. Relatório de Atividades. São Paulo: Instituto Unibanco, 2009. Disponível em: <http:// www.institutounibanco.org.br/wp-content/uploads/2013/09/rel_atividades_IU__ 2009.pdf>. Acesso em 10 out. 2018. 
MONTEIRO, M. Relação público-privada na Educação Básica no Brasil: uma análise da proposta do Instituto Unibanco para o Ensino Médio público. In: PERONI, V. M. V. (Org.). Redefinições das fronteiras entre o público e o privado: implicações para a democratização da educação. Brasília: Liber Livro, 2013. p. 276-289.

NEVES, L. M. W. A sociedade civil como espaço estratégico de difusão da nova pedagogia da hegemonia. In: NEVES, L. M. W. (Org.). A nova pedagogia da hegemonia: estratégias do capital para educar o consenso. São Paulo: Xamã, 2005. p. 85-125.

PERONI, V. M. V. A gestão democrática da educação em tempos de parceria entre o público e o privado. In: Pro-Posições, Campinas, v. 23, n. 2 (68), p. 19-31, maio/ago. 2012. Disponível em: <http://www.scielo.br/pdf/pp/v23n2/a03v23n2.pdf>. Acesso em: 3 de fev. 2013.

PERONI, V. M. V. A privatização do público: implicações para a democratização da educação. In: PERONI, V. M. V. (Org.). Redefinições das fronteiras entre o público e o privado: implicações para a democratização da educação. Brasília, DF: Liber Livro, 2013. p. 9-32 e p. 276-289.

RAMOS, M. N. O currículo para o ensino médio em suas diferentes modalidades: concepções, propostas e problemas. Educação \& Sociedade, Campinas, v. 32, n. 116, p. 771-788, jul.-set. 2011. Disponível em: <http://www.scielo.br/pdf/es/v32n116/a09v32n116.pdf>.. Acesso em: 4 de nov. 2018.

ROBERTSON, S.; DALE, R. Regulação e risco na governação da educação. Gestão dos problemas de legitimação e coesão social em educação nos estados competitivos. In: Educação, Sociedade \& Culturas, n. 15, Universidade do Porto, Portugal, 2001, p. 117-147. Disponível em: <http:// www.fpce.up.pt/ciie/revistaesc/ESC15/15-7-roberston.pdf>. Acesso em: 02 out. 2018.

ROBERTSON, S.; VERGER, A. A Origem das parcerias público-privadas na governança global da educação. In: Revista Educação e Sociedade, Campinas, v. 33, n. 121, p. 1133-1156, out.dez. 2012. Disponível em: <http://www.scielo.br/pdf/es/v33n121.a12v33n121 .pdf>. Acesso em 02 out. 2018.

SILVA, M. R. Currículo e Competências. A formação administrada. São Paulo: Cortez, 2008.

- O Programa Ensino Médio Inovador como política de indução a mudanças curriculares: da proposta enunciada a experiências relatadas. Educação em Revista. Belo Horizonte, v.32, n.02, p. 91-110, Abril-Junho 2016. Disponível em: http://www.scielo.br/ scielo.php?pid=S0102$46982016000200091 \&$ script=sci_abstract\&tlng=pt. Acesso em 29 out. 2018.

\section{Contato para correspondência:}

Monica Ribeiro da Silva.E-mail: monicars@ufpr.br 


\section{Notas}

1 Compreendemos que além das divisões entre classes sociais, na sociedade contemporânea, existem variados grupos sociais, que nem sempre se identificam com uma das classes sociais, trabalhadores ou capitalistas, apesar, de modo geral, pertenceram a elas. Assim como, compreendemos que dentro de uma classe social existem vários grupos que competem por poder e por pela ampliação dos seus interesses.

2 No decorrer do trabalho, utilizamos essa acepção de público, ou seja, a de "ser para todos", fazendo, assim, o contraponto à concepção de privado: de "ser para o individual e/ou de ser para o particular". Com base em Gramsci, entendemos que essa condição de "ser para todos", de "bem-comum", numa sociedade dividida em grupos e classes sociais, tende a ser limitada. Porém, Gramsci, ao analisar a sociedade civil, percebe que as diferentes organizações (aparelhos de hegemonia) podem buscar a condição pública no sentido de contemplar a todos.

3 A elaboração gramsciana de Estado, também é chamada por autores como Coutinho (2014) de "Estado ampliado" ou "Estado integral". Utilizaremos, também, essas expressões ao nos referirmos à concepção gramsciana de Estado (sociedade política e sociedade civil).

4 As ditaduras, em geral, são expressões de falta de hegemonia do grupo que domina o aparelho estatal, porque ao não terem o consenso social, usam a coerção. Coutinho (2006, p. 182) explicita o sentido dado pela "ditadura sem hegemonia", no caso brasileiro: "[...] é o fato de que nesse tipo de Estado, existe certamente uma classe dominante, que controla direta ou indiretamente o aparelho governamental, mas o projeto político dessa classe não tem respaldo consensual do conjunto ou da maioria da sociedade. Nesse caso, lembra ainda Gramsci, pode-se falar de hegemonia de uma fração da classe dominante sobre as outras frações, mas não do conjunto dessa classe sobre o conjunto de classes subalternas. Portanto, os cinquenta anos que vão de 1930 e 1980 conhecem um tipo de Estado burguês que se caracteriza, em sua maior parte, pela presença de uma dominação sem hegemonia. É este o caso, evidentemente, dos momentos de ditadura explícita, como os que vão de 1937 a 1945 e de 1964 a 1985, que cobrem cerca de trinta anos".

5 O Ensino Médio Integrado, articulação entre formação geral e formação profissional, fortaleceu-se como possibilidade de organização do Ensino Médio, a partir da revogação do Decreto 2.208/97 e a homologação do Decreto 5.154/04 que constituiu o Ensino Médio Integrado como uma das possibilidades de Educação Profissional técnica. Traz como fundamento o conceito de politécnica e de integração entre formação científica básica e formação técnica e tecnológica.

6 O Todos pela Educação é a principal organização do empresariado brasileiro que representa as suas intenções diante da educação pública. A junção dos projetos das instituições mantenedoras do TPE demonstra que o empresariado trabalha em diferentes etapas da educação básica, educação superior e modalidades da educação. Cria uma espécie de "sistema de educação" paralelo ao oficial que ora se articula às políticas públicas já existentes e/ou sugere a elaboração de outras. Ora ações independentes às políticas educacionais, inclusive, desconsiderando normativas legais, como as resoluções curriculares.

7 Sobre o Centro de Estudos: "O espaço mantém parcerias com escolas estaduais localizadas em seu entorno - a Rede de Educação - e funciona como laboratório de experiências educacionais, desenvolvido pelo Instituto Unibanco, como, por exemplo, o Projeto Jovem de Futuro, cuja fase piloto iniciou-se em escolas da Rede" (INSTITUTO UNIBANCO, 2007, p. 23). 
$8 \quad[. .$.$] um sistema social no qual o sucesso do indivíduo depende principalmente de$ seu mérito - de seus talentos, habilidades e esforço. A ideia da meritocracia tem servido como IDEOLOGIA, baseada no argumento de que a desigualdade social resulta de mérito desigual, e não de preconceito, discriminação e opressão (JOHNSON, 1997, p. 146). A meritocracia, entendida como ideologia, refere-se ao mérito ou à possibilidade de cada indivíduo ser notado, reconhecido socialmente por meio da sua capacidade, ou, ainda, se refere ao destaque que cada indivíduo conquista em certa hierarquia devido ao seu talento e à sua dedicação (BARBOSA, 2006). 